\title{
Mapping the productive sands of Lower Goru Formation by using seismic stratigraphy and rock physical studies in Sawan area, southern Pakistan: a case study
}

\author{
Khyzer Munir • M. Asim Iqbal • Asam Farid • \\ Syed Mohammad Shabih
}

Received: 11 May 2010/Accepted: 6 January 2011/Published online: 24 February 2011

(C) The Author(s) 2011. This article is published with open access at Springerlink.com

\begin{abstract}
This study has been conducted in the Sawan gas field located in southern Pakistan. The aim of the study is to map the productive sands of the Lower Goru Formation of the study area. Rock physics parameters (bulk modulus, Poisson's ratio) are analysed after a detailed sequence stratigraphic study. Sequence stratigraphy helps to comprehend the depositional model of sand and shale. Conformity has been established between seismic stratigraphy and the pattern achieved from rock physics investigations, which further helped in the identification of gas saturation zones for the reservoir. Rheological studies have been done to map the shear strain occurring in the area. This involves the contouring of shear strain values throughout the area under consideration. Contour maps give a picture of shear strain over the Lower Goru Formation. The identified and the productive zones are
\end{abstract}

K. Munir

King Abdulaziz City for Science and Technology (KACST), P.O. Box 6086, Riyadh, Saudi Arabia

e-mail: kmunir@kact.edu.sa

M. A. Iqbal $(\square)$

Physical Science and Engineering Division, King Abdullah University of Science and Technology, P.O. Box 2104, Building

1 Room 3209, Thuwal, 23955-66900 Jeddah, Saudi Arabia

e-mail: asim.iqbal@kaust.edu.sa

\section{A. Farid}

Department Of Petroleum Geosciences, The Petroleum Institute, P.O. Box 2533, Ruwais Building, Abu Dhabi,

United Arab Emirates

e-mail: afraid@pi.ac.ae

\section{S. M. Shabih}

Norwegian Energy Company ASA (NORECO),

Nykirkebakken 2, 4025 Stavanger, Norway

e-mail: syed.mohammad.shabih@noreco.com described by sands, high reflection strengths, rock physical anomalous areas and low shear strain.

Keywords Stratigraphy - Rock physics - Rheology · Sawan

\section{Introduction}

Sawan field lies in southern Indus Basin that is extending between $24^{\circ}$ and $28^{\circ} \mathrm{N}$ latitude and from $66^{\circ} \mathrm{E}$ longitude to the eastern boundary of Pakistan (Zaigham and Mallick 2000). To go with the prominent convergence and the late Paleocene collision between the Indian and the Eurasian plates in the north Pakistan, the area was also affected by the translation between Indian plate and Afghan Craton in the northwest (Banks and Warburton 1986) and by territory convergence between Arabian Plate and Afghan Craton (Zaigham and Mallick 2000). The effect of the western rift margin of the Indian plate dominance can be observed in the form of many normal fault and horst and associated grabens on the seismic sections and also in the form of Sibbi-Jacobabbad, Khairpur, Mari-Kandkot highs as its surface expressions (Michalchuk 2006). The study area to go with other parts of southern Indus Basin has thick Mesozoic-Tertiary sedimentary sequences overlain by Quaternary sediments (Kadri 1995). The area was tectonically stable until the Jurassic and probably Early Cretaceous but rifting started to occur during Late Cretaceous and Early Paleocene, the effects of which can be seen on seismic sections, where the post-Eocene strata are either not affected or very less deformed. Information about the description and deposition of various rock units is available in literature (e.g. Kadri 1995; Shah 1977). The present study is confined to the discussion on Cretaceous rock with 
special reference to the Goru Formation. Cretaceous rocks are widely distributed in different parts of Lower Indus Basin. There is wide range of lithological heterogeneity in these rocks, mainly attributed to change in sediment supply and environmental conditions. The thick $(+760 \mathrm{~m})$ Neocomian Sembar Formation consists of black shale, which is silty and has interbeds of black siltstone and nodular argillaceous limestone. There are some sandstone beds as well. The siliciclastics were probably derived from the Indian Shield and have sand in more abundance in the eastern parts of the basin, while the western part is more silty and shaley (Kadri 1995). The Aptian-Albian Goru Formation is mainly composed of black to gray and locally maroon shale/mudstone in the lower part. The upper part of Lower Goru is composed of sandstone that is of significant importance in terms of its reservoir character in different parts of the southern Indus Basin, to go with Sawan area. Sandstone is rare in the upper part of the Formation that has shale as dominant lithology. The name Lower Goru is used for the lower sandy part of the Formation, whereas the upper shale unit is termed as Upper Goru (Kadri 1995). The generalized depositional environments of the Formation appear to be relatively deep marine, with minor shallow phases of benthic rich fauna being indicated. The Lower Goru may, however, represent barrier to deltaic environments.

The overlying Cretaceous rocks include light gray, white colour thin-bedded argillaceous Parh Limestone that is overlain by mixed siliciclastics and carbonates of Mughal Kot Formation while Fort Munro Formation with its sandy, argillaceous limestone and the overlying Pab Sandstone being the other younger Cretaceous rock units in the Southern Indus Basin

Sawan gas field Fig. 1 is one of the major gas producing areas with early-late Cretaceous Lower Goru Formation acting as the potential reservoir here. During the past two decades these sands have emerged to be a significant hydrocarbon producer from the Middle and Lower Indus Basin in Southern Pakistan. The Sawan gas field comprises total proven reserves of 2-2.5 TCF gas. Total of five wells have been used in the study. The Lower Goru Formation is

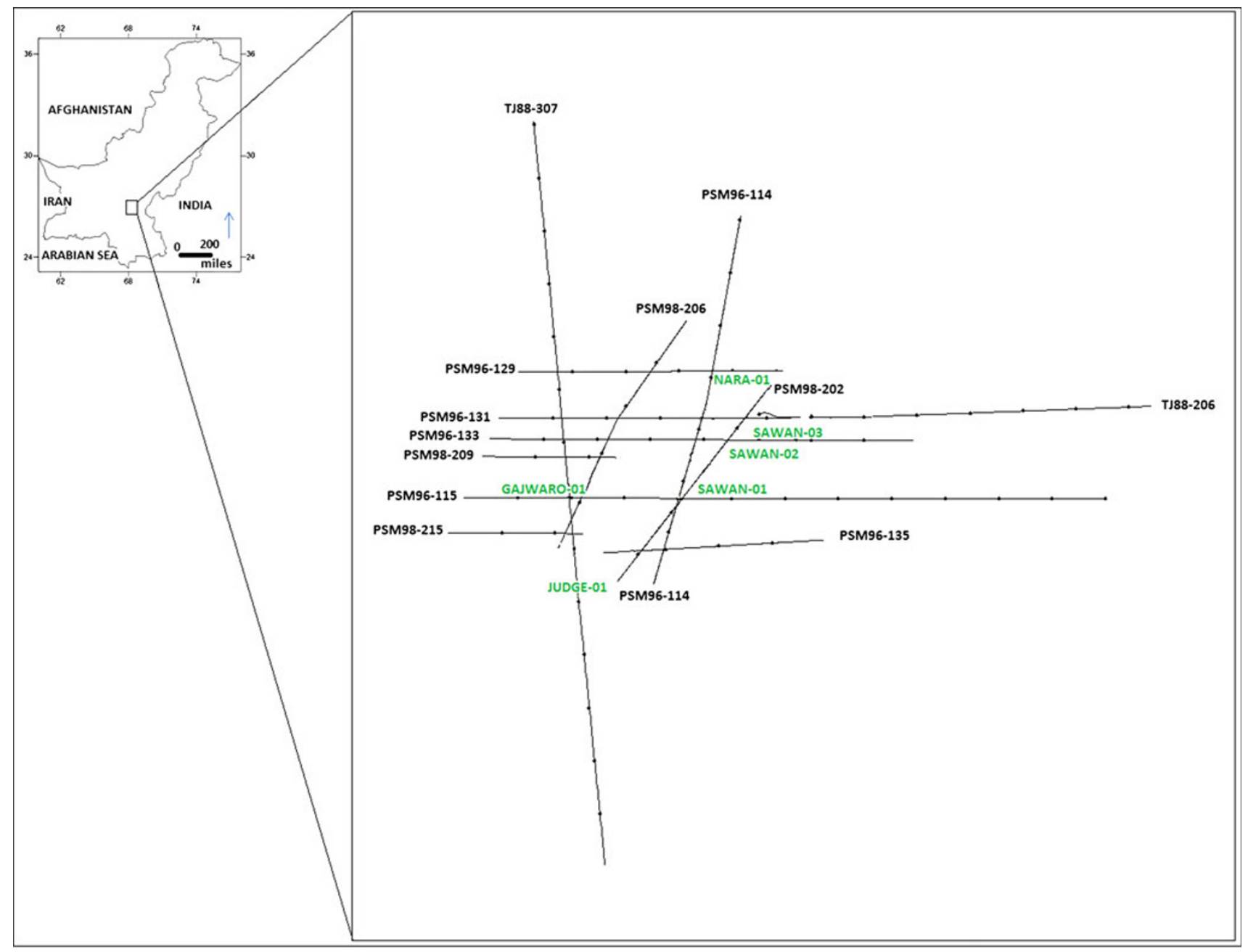

Fig. 1 Location map of the studied area 
found to be productive in only three wells out of six (i.e. Sawan-01, Sawan-02 and Sawan-03). The other three wells (Gajwaro-01, Judge-10 and Nara-01) are unproductive within the Lower Goru Formation C Sand horizon. Seismic stratigraphy approach has been used to understand the stratigraphic system of the area. The analysis of seismic stratigraphy, seismic attributes, rock physics parameters helps us to delineate the sands which can act as reservoirs in the area.

\section{Seismic sequence stratigraphy}

Seismic sections provide the best means of recognizing onlap and toplap patterns within the depositional sequences and well control can provide data for the distinction between coastal and marine facies within the sequences (Vail et al. 1977). The seismic stratigraphic interpretation method depends upon the observation of all the seismic parameters (continuity, amplitude, apparent frequency, configuration, reflection terminations, search for unconformities, and their classification within uniform units to define seismic "facies" and then on the 3D analysis of their lateral and vertical variations) (Ravenne 2002).

The horizons are identified by using the synthetic seismograms prepared for Sawan-01 and Gajwaro-01 wells. The lateral changes in facies are mapped using the sequence stratigraphic analysis after Ahmed et al. 2004. The seismic stratigraphic interpretation is based on regional E-W seismic lines. Figure 3 shows the interpretation over line PSM96-114. The late Jurassic Chiltan Limestone can be recognized easily as a strong reflector on these lines at around $2.5 \mathrm{sec}$ TWT. Three sequence boundaries have been identified in Fig. 2 (i.e. SB1, SB2 and SB3). SB-1 is recognized as the first sequence boundary that exists within Sembar Formation and gets downlap at the top of the Chiltan.

The sequence up to SB1 comprises the downlapping progrades of the Sembar above Chiltan. SB2 is identified as the second sequence boundary. The sequence between SB1 and SB2 is a lowstand system tract (LST) dominated by the slopping fans. SB3 is the third sequence boundary that exists within the Lower Goru Formation. SB2 is followed by a gradual rise in sea level until it approaches a maximum flooding surface (MFS) between SB2 and SB3. The onlapping pattern demonstrates a transgressive nature for the sequence.

There are prograding sands trapped in the A, B and C horizons of the Lower Goru Formation. These can be easily identified on the seismic sections as bright spots as shown in Fig. 3.

\section{Sand shale sequences of Lower Goru Formation}

The Early Cretaceous silciclastics of Sembar and Goru Formations were deposited on the top of an extensive carbonate platform (Chiltan Limestone). Sembar-Goru Play is an important petroleum system of the studied area. Various stratigraphic traps are found, most of which are gas

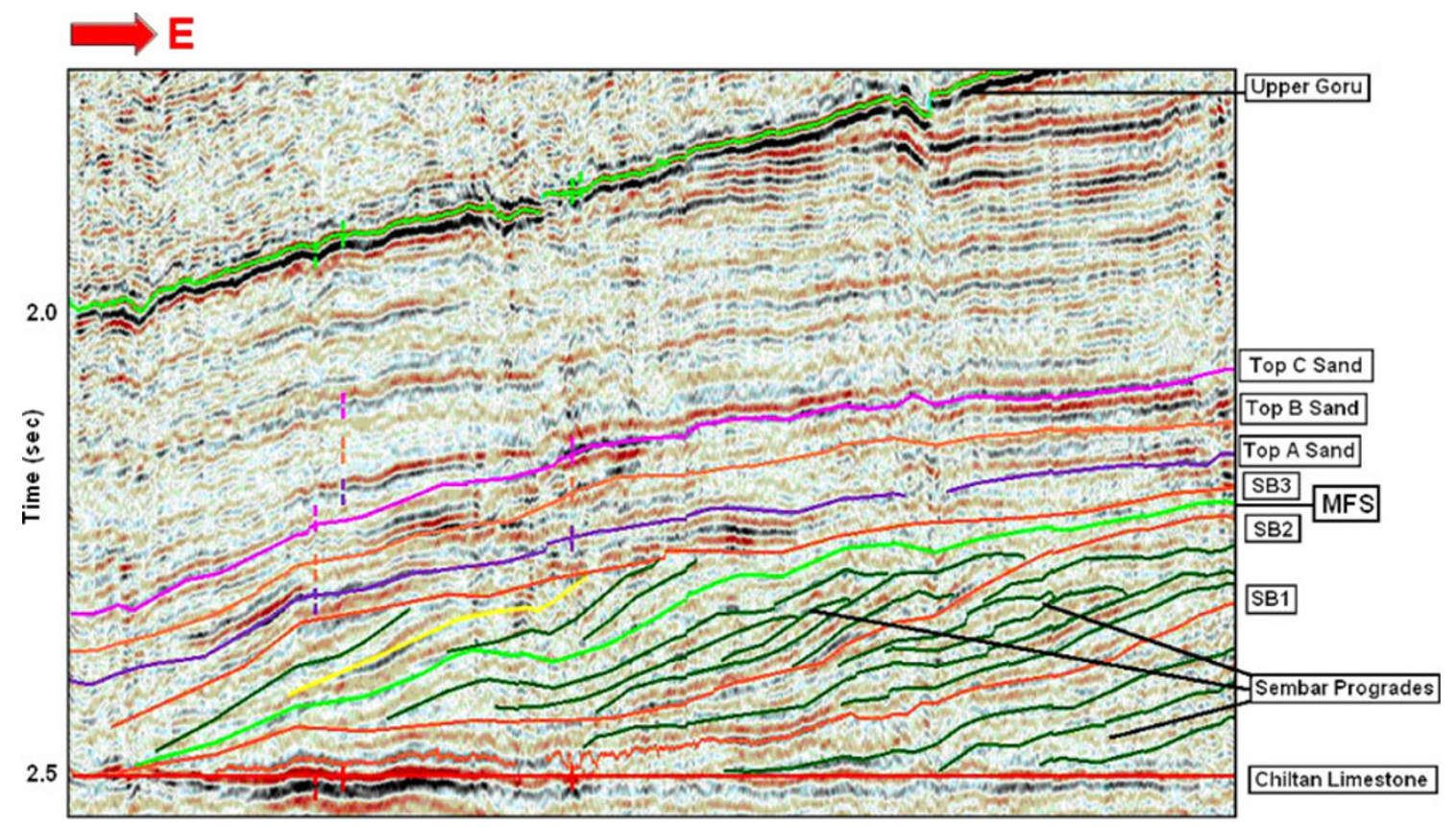

Fig. 2 Sequence stratigraphic interpretation on an EW regional seismic line. The section is flattened on the Chiltan Limestone. Three sequence boundaries, MFS and reflection termination patterns like onlaps, downlaps and topsets are clearly visible (after Ahmed et al. 2004) 


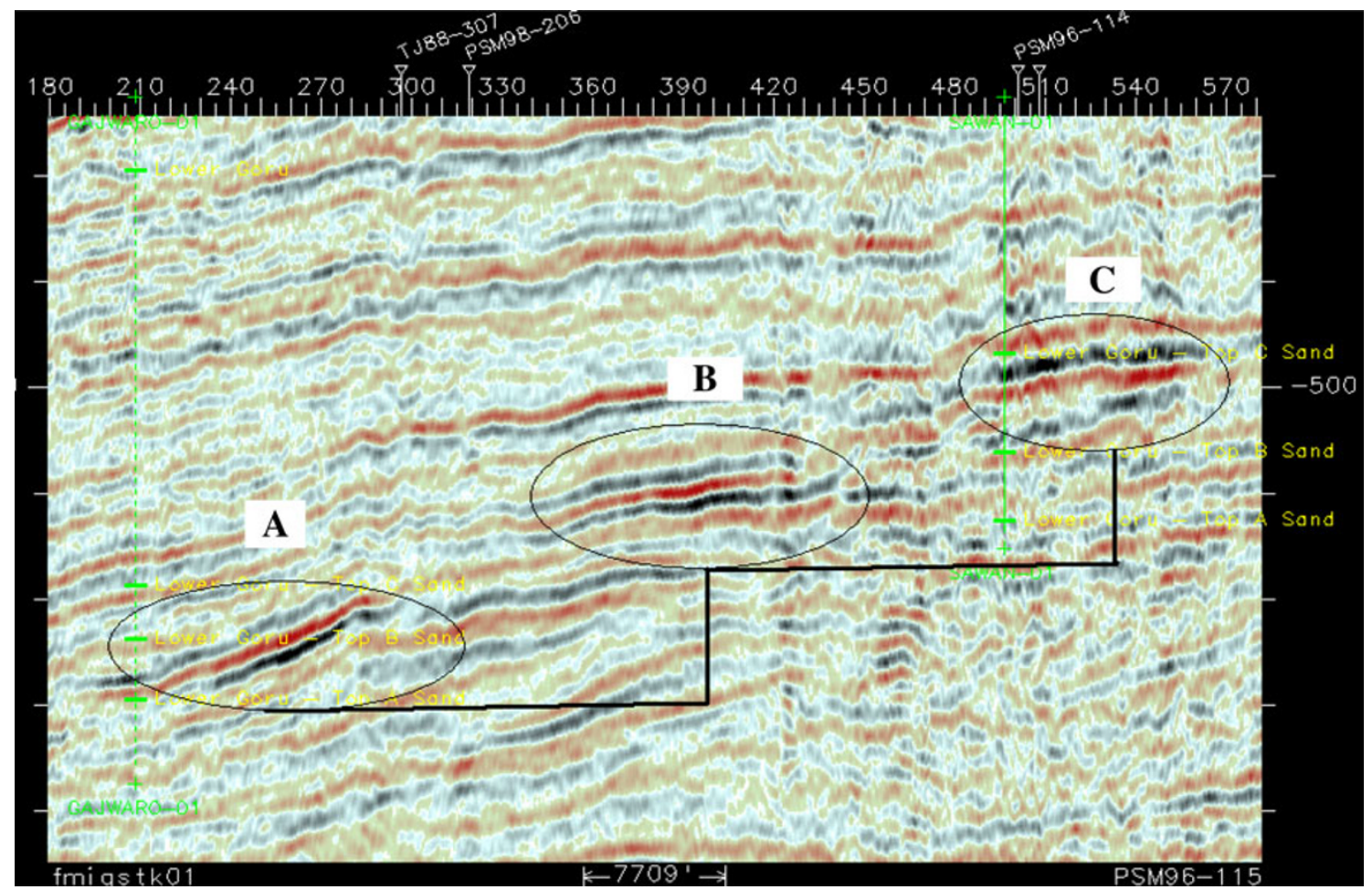

Fig. 3 Bright spots seen in the A, B and C Sand horizons of Lower Goru Formation. Bright spots are named accordingly to the horizons in which they occur

producing. Lower Goru is divided into three members or intervals "A", "B" and "C" (Fig. 3). Above Sembar and Goru Formations, lay the Tertiary Ranikot Formation and Sui Main Limestone. Goru Formation consists of interbedded sandstone, shale and siltstone with very thin-bedded limestone (Kazmi and Jan 1997).

The bottom layers of the Lower Goru Formation consists of sands interlayered with shales which are further divided into as Sand A, Sand B, Sand C and Sand D in the studied area as shown in Fig. 4. The upper portion of Lower Goru comprises thick shales which are acting as regional seal. Sembar Formation acts as a source rock for this petroleum system. Sands B and C are serving as a potential gas reservoirs in this area.

Figure 5 is developed from Fig. 2 and shows the depositional pattern of Sembar-Goru petroleum system. The system has been deposited on the Chiltan Limestone which acted as the platform for deposition. The Sembar deposition is marked by various drops and rise in sea level. Between SB1 and SB2 is the SEQ A which demonstrated the lowstand time. It constitutes the lowstand slope fan and the prograding delta. The delta downlaps over the slope fan. Between SB2 and MFS is the SEQ B and is the highstand time. Between MFS and SB3 is the SEQ C and is the lowstand time. It is characterised by lowstand fan and prograding delta. After SB3 lithologies have been termed as SEQ D and constitute Lower Goru deposition. Lower

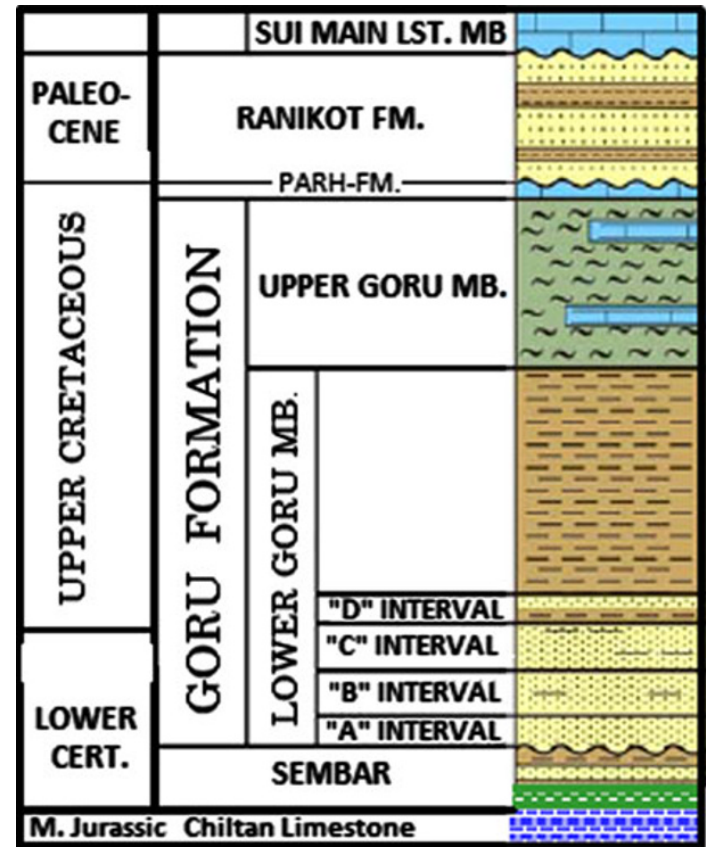

Fig. 4 The stratigraphic column showing the subdivisions of Lower Goru Formation into Sand intervals A, B, C and D after Ahmed et al. 2004

Goru horizons A Sand, B Sand and C Sand are dominated by progrades. Various sand bodies have been identified by these reflection patterns. 


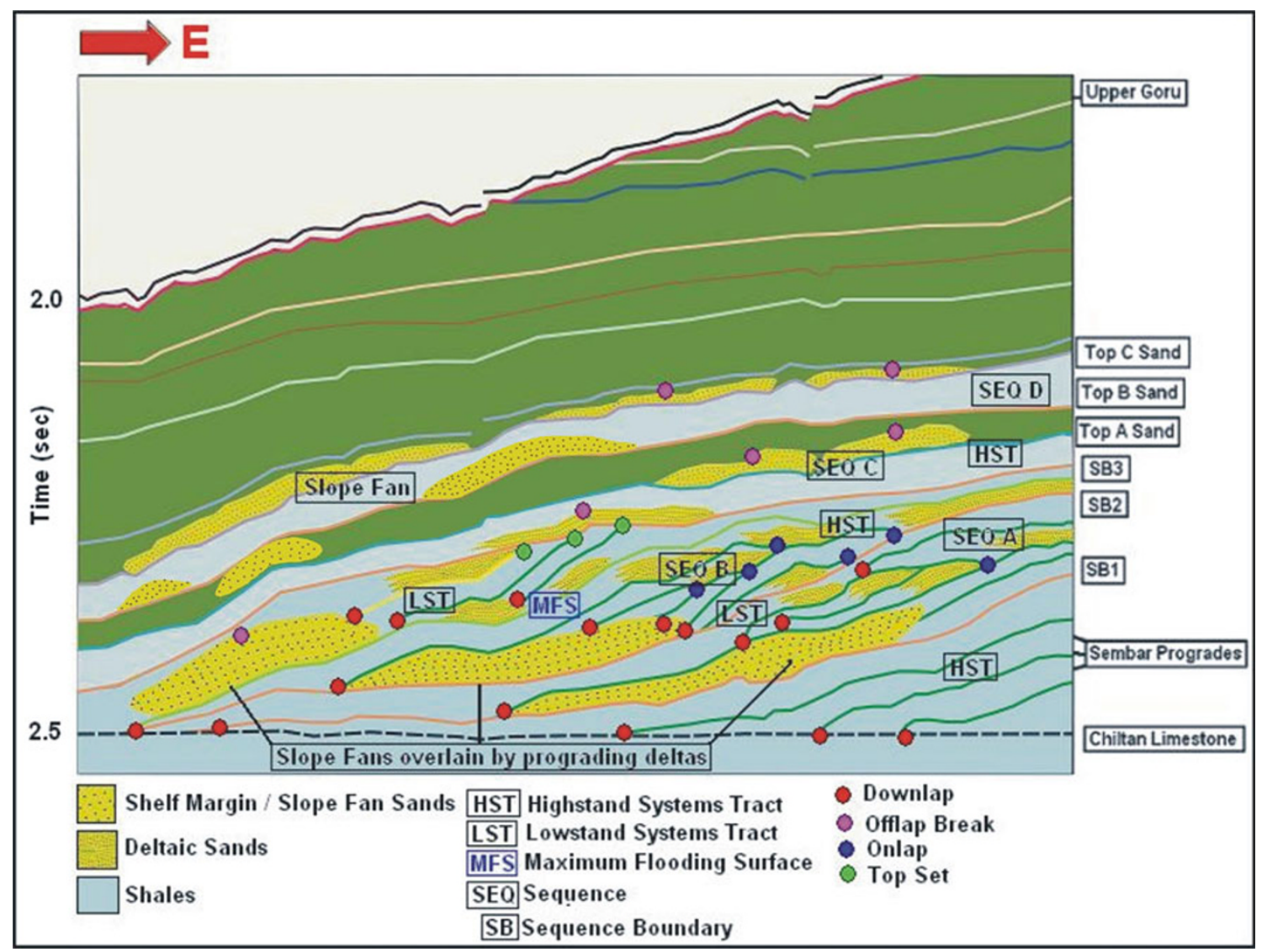

Fig. 5 Depositional pattern of Lower Goru Formation (after Ahmed et al. 2004)

\section{Rock physics}

Well log data and petrophysical analysis provide the basic input for the rock physics analysis and the generation of different lithology classes (Bachrach et al. 2004). Rock physics modelling has been performed by Gommesen et al. 2004 to study porosity and fluid effects on the elastic properties. According to models the elastic properties of the studied formation are primarily controlled by porosity and to secondary degree by the changes in fluids.

The seismic interval velocities from different CDP locations, corresponding to the Lower Goru interval are employed for a series of mathematical calculations for calculating different rock physics parameters, such as bulk modulus, and Poisson's ratio. Two-way seismic times and their corresponding interval velocities $(\mathrm{P})$ are noted at all the CDP locations. They are then converted to the $\mathrm{S}$-wave velocities and densities using the Castagna's and Gardener's equations, respectively. This data is finally used for calculating each of the rock physics parameter.

Royle and Bezdan 2001 have demonstrated the comparison of shear wave velocity estimation techniques.

The equation $V_{\mathrm{p}}=1.16 V_{\mathrm{s}}+1.36(\mathrm{~km} / \mathrm{s})$ by Castagna et al. 1985 has been used to convert $\mathrm{P}$ wave velocities to
S-wave velocities. The relationships between compressional wave and shear wave velocities were discussed by Castagna et al. 1985 for clastic silicate rocks. There has been increased use of $V_{\mathrm{p}}, V_{\mathrm{s}}$ and $V_{\mathrm{p}} / V_{\mathrm{s}}$ in seismic exploration for estimation of porosity, lithology and saturating fluids in particular seismic intervals (Castagna et al. 1985).

Figure 6a shows the crossplots for the Sawan-01 well and Fig. $6 \mathrm{~b}$ shows the crossplots for Gajwaro-01 well.

Each of the mentioned rock physics parameter is discussed separately in the following.

Bulk modulus

Primary and shear wave velocities are used in the following equation to calculate the bulk modulus which is the measure of compressibility

$\mathrm{K}=\rho\left(V_{p}^{2}-4 / 3 V_{s}^{2}\right)$

where $\rho$ is the density obtained from the equation density $=0.31 \times\left(V_{\mathrm{p}}\right)^{1 / 4}$ as demonstrated by Gardner et al. 1974. $V_{\mathrm{p}}$ is the primary wave velocity and $V_{\mathrm{s}}$ is the shear wave velocity obtained from $V_{\mathrm{p}}$.

Using this equation we calculated the bulk modulus for our potential reservoir, Sand C, for all the seismic lines 

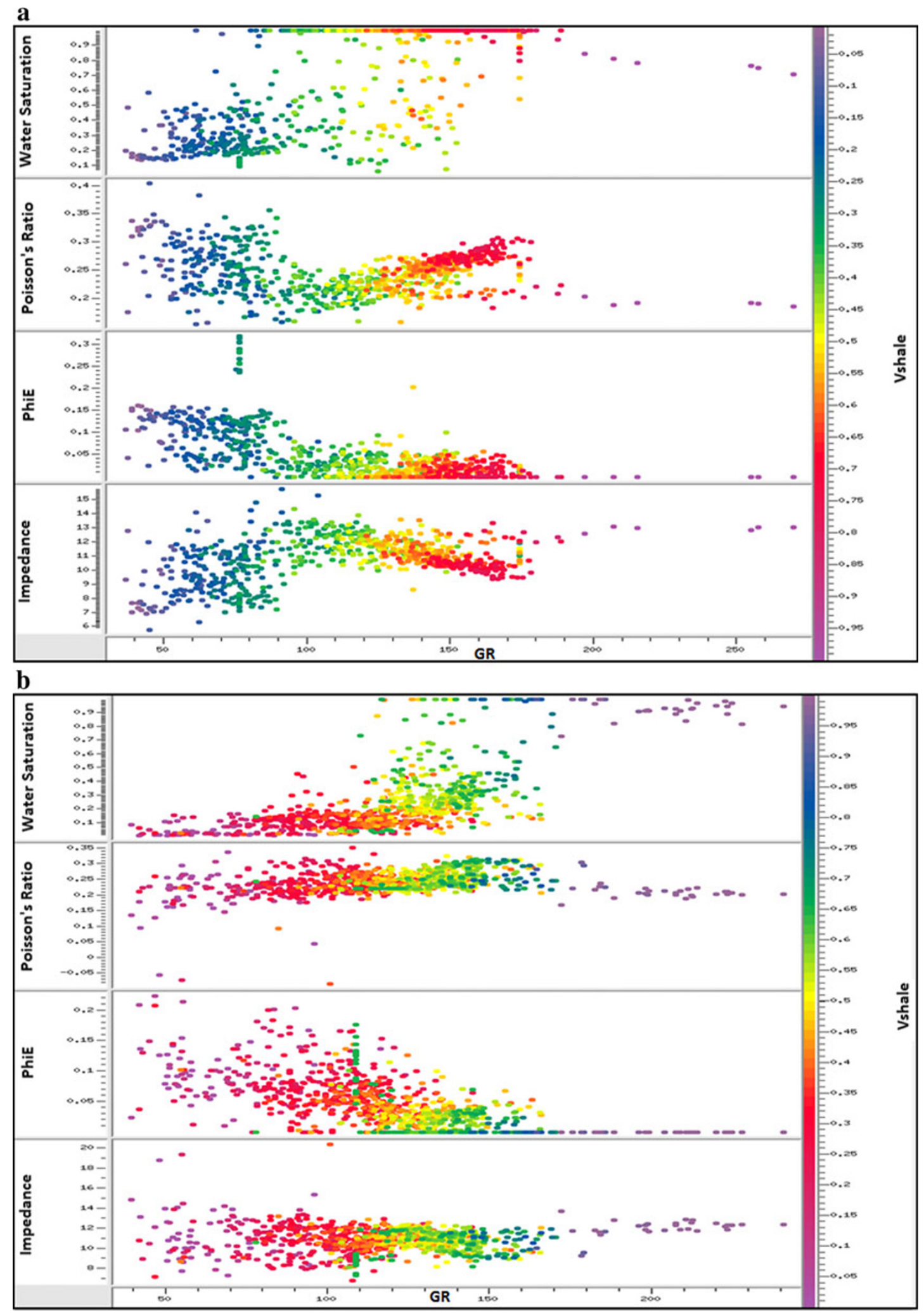

Fig. 6 a Low GR, low impedance, good effective porosity, Poisson's ratio $(0.25-0.35)$ and low water saturation suggest that the reservoir is productive in Sawan-01 well. b The reservoir is marked by low effective porosity, relatively higher impedance and lower Poisson's ratio $(0.2-0.3)$ for Gajwaro-01 well 
present in the study area. These values are then contoured in Fig. 7, to highlight the anomalous zones with low bulk modulus values when compared with the surroundings. The producing C Sand exhibit the high values of bulk modulus apart from places where hydrocarbons occur. Figure 7 represents the variation of bulk modulus in the study area.

\section{Poisson's ratio}

This is basically the ratio of compressibility and rigidity, or the readiness of a compressed material to bulge. It has been calculated at the same location and time interval as the bulk modulus, using the following equation

$v=0.5\left(V_{p}^{2}-2 V_{s}^{2}\right) /\left(V_{p}^{2}-V_{s}^{2}\right)$

Therefore, Poisson's ratio for Sand C is calculated on all the seismic lines and is then contoured Fig. 8. This map differentiates the dry sands and gas sands on the basis of low and high value contours. The values of the gas saturated areas are in between 0.28 and 0.31 which are confirmed by well Sawan-01 which is 0.28 for the same interval.

\section{Rheological studies}

Rheological studies are carried out to understand the occurrence of stress and strains on Lower Goru sands in the study area. These include the measurement of longitudinal strain, shear strain and total stresses which are discussed individually in the following.

Shear strain

In order to calculate the shear strain, the angle which all the faults form with the vertical is required. Shear strain will in fact be the tangent of that particular angle, and it is calculated at all the points where the major faults are evident. Shear strain values are also contoured to show the degree of shear (angular) deformation in the area as described on Fig. 9. It also shows that the productive wells lies in the low shear strain area and the nonproductive wells in the high shear strain area.

\section{Uncertainty analysis}

Figure 10 shows the correlation between the velocities derived from sonic log (Sawan-01) and interval velocities for the line PSM96-115. The figure shows a fair correlation between the velocities. Also, Fig. 11 shows a correlation between the velocities derived from sonic log (Gajwaro-01) and interval velocities for the line PSM96-115. Figure shows a reasonable correlation between the velocities. The correlation for both the wells suggests that the calculations done for the rock physical studies are reasonable.

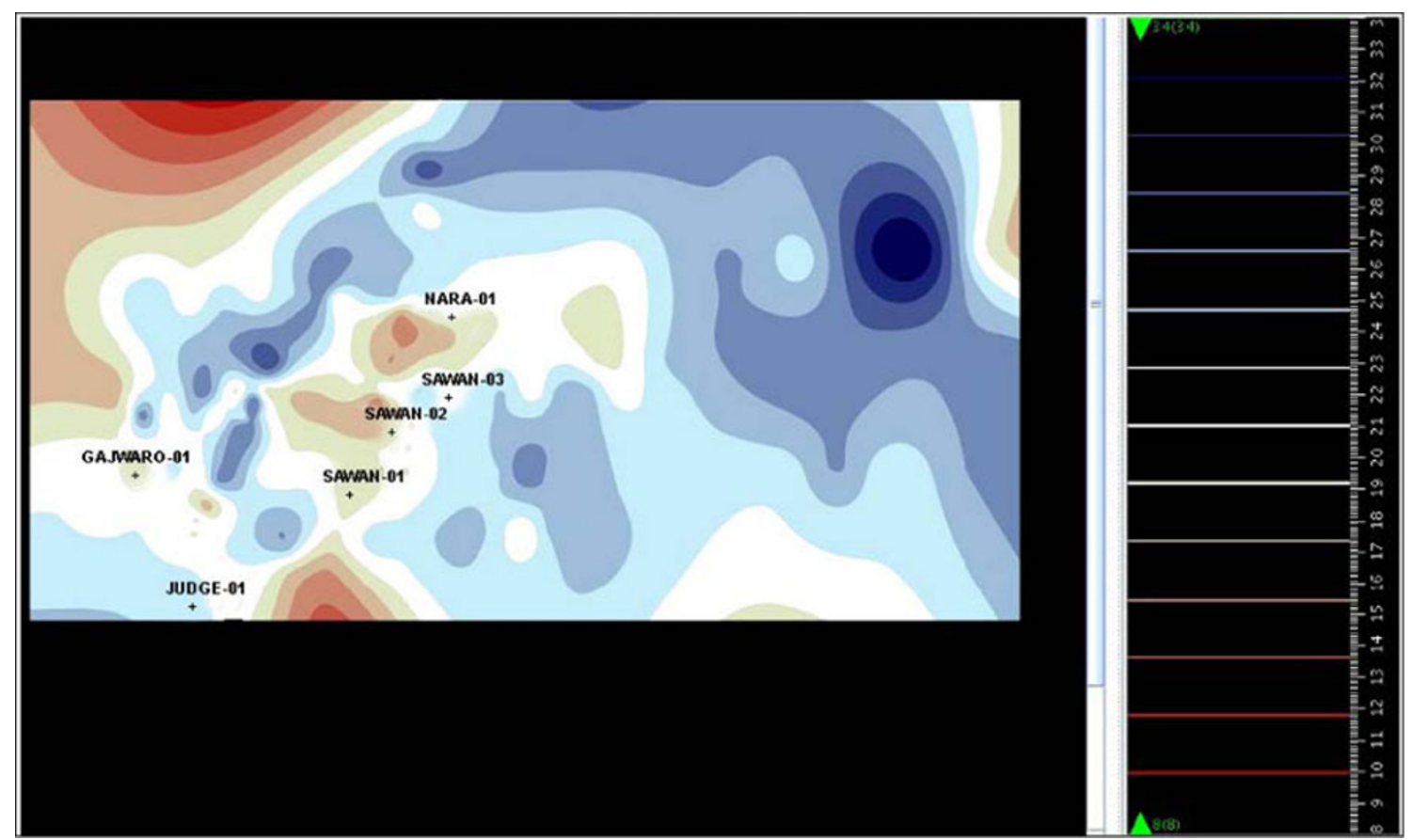

Fig. 7 Contour map prepared for bulk modulus values estimated for the whole area. It is clear from the map that all the six wells fall in the anomalous zone with comparatively low values 


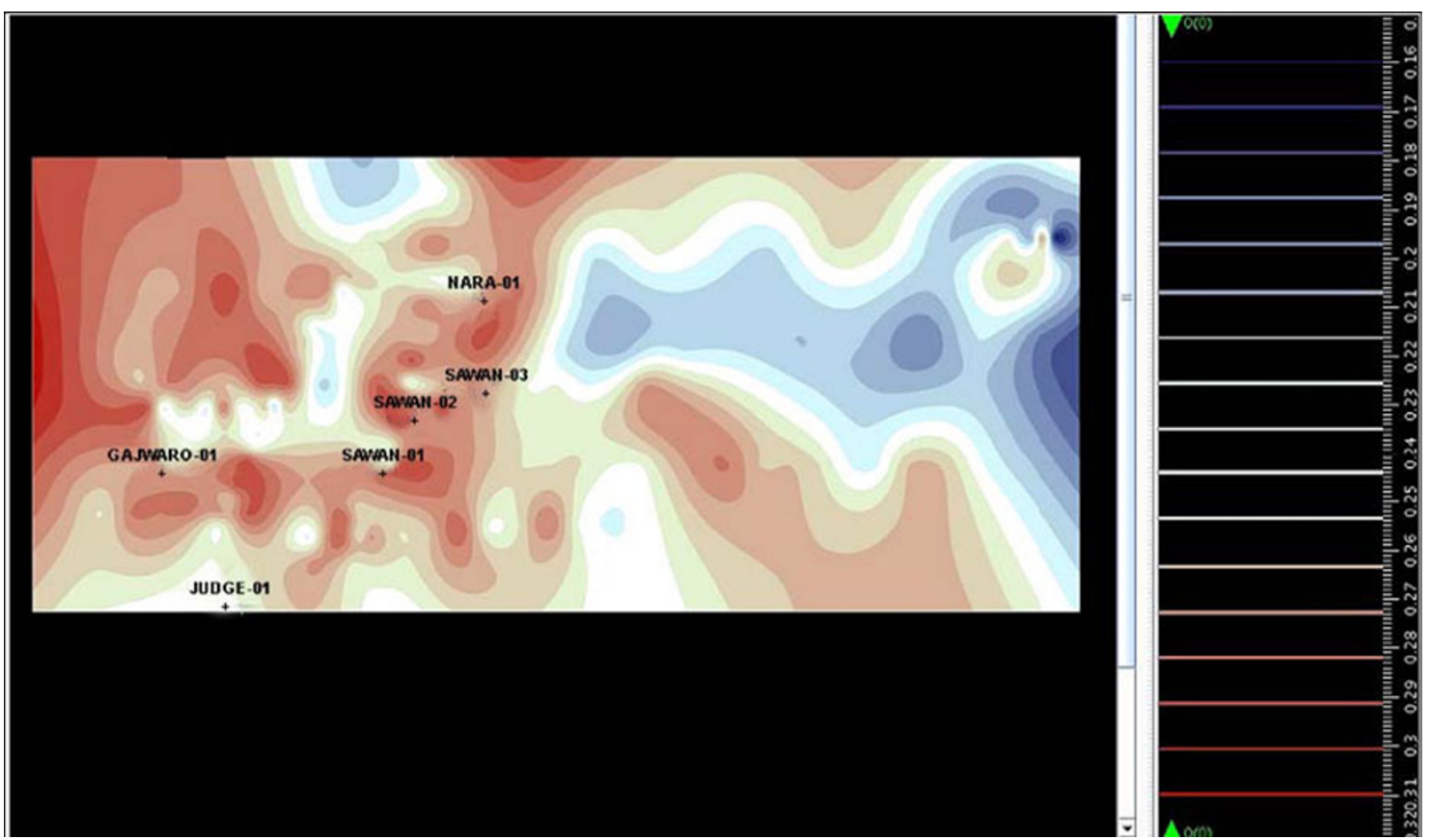

Fig. 8 Contour map prepared for the Poisson's ratio values through out the study area. It is evident that all the six wells lie in a zone where the Poisson ratio values are on the higher side. This shows that the sands encountered at these well locations are filled with gas
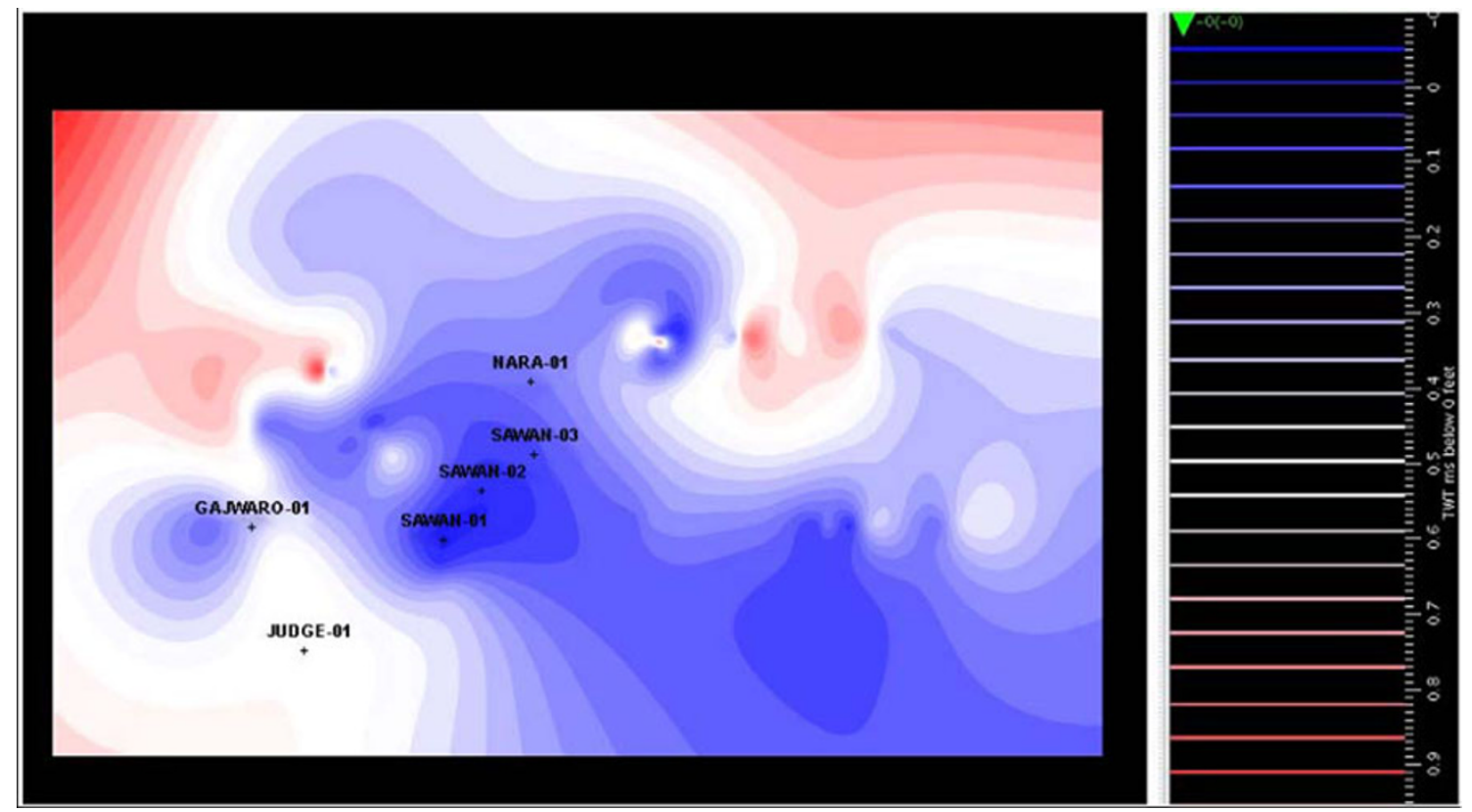

Fig. 9 The contour map prepared for the shear strain values in the studied area. It is clear from the map that the strain produced at dry well (Gajwaro-01, Judge-01 and Nara-01) locations is relatively more than the producing gas wells

Since the aim of the study was to map the productive sands of the Lower Goru Formation, Figs. 7 and 8 shed some light on the occurrence of productive sands. The high values of Poisson's ratio and low values of bulk modulus suggest the gas saturation for the sands as calibrated with the wells. The reservoir is bounded by the contour values $(0.28-0.31)$ of Poisson's ratio. The map also highlights favourable areas for hydrocarbon saturation in the study area. The areas with Poisson's ratio values greater than 0.28 other than the wells should be evaluated in detail for possible hydrocarbon accumulations. 
Fig. 10 The crossplot shows the correlation between the velocities derived from sonic $\log$ (Sawan-01) and interval velocities for the line PSM96115. Figure shows a fair correlation between the velocities

Fig. 11 The crossplot shows the correlation between the velocities derived from sonic $\log$ (Gajwaro-01) and interval velocities for the line PSM96115. Figure shows a fair correlation between the velocities
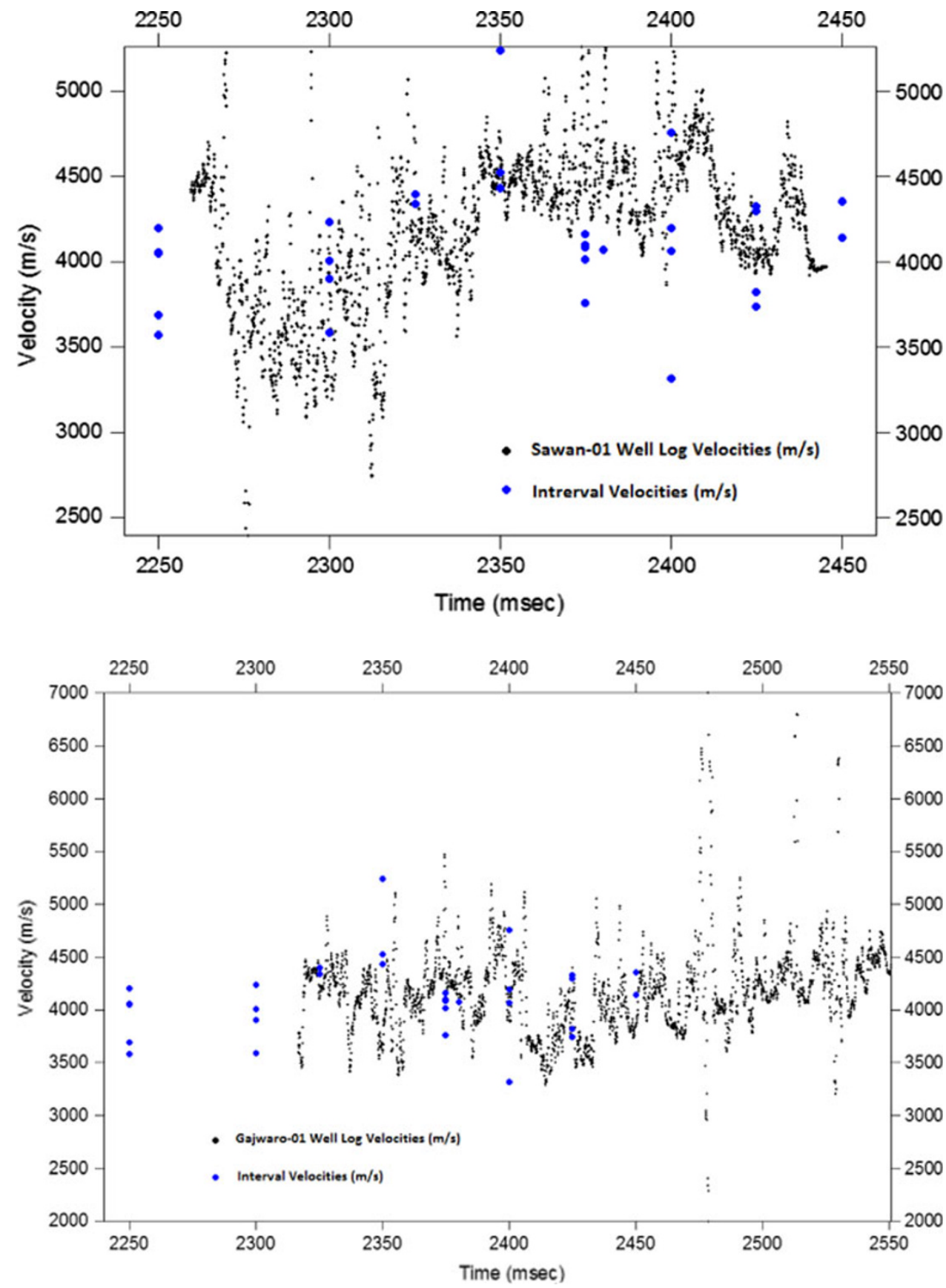

\section{Conclusions}

The following conclusion can, therefore, be drawn:

1. The bulk modulus map (Fig. 7), confirms that the locations where the above-mentioned wells were drilled falls within low value contours, thus, favouring the hydrocarbon presence over there.

2. The Lower Goru Sands are confirmed to be gas saturated through a Poisson's ratio contour map (Fig. 8), that suggest high values for these well locations as compared with Sawan-01 well data.
3. A correlation has been established between the sequence stratigraphic studies with the bulk modulus and the Poisson's ratio maps, for marking the gas saturation zones. Therefore, the relatively higher Poisson's ratio closures favours the occurrence of hydrocarbons.

4. The Poisson's ratio map can be compared to Fig. 5 which suggests a match between the bright spots and high Poisson's ratio closures.

5. The shear strain contour map implies that the producing gas wells (Sawan-01, Sawan-02, Sawan-03) lies in 
the low shear strain area whereas the dry wells (Gajwaro-01, Nara-01) falls relatively in the relatively high shear strain area.

6. The reservoir is productive in low strain area, as this is necessary for the trap generation.

7. The well Gajwaro-01 lies considerable distance away from the centre of bright spot A (Fig. 3) which is attributed to its nonproduction, although gas shows have been reported for the well.

8. Study suggests that a bright spot B could be saturated with gas and may yield production if evaluated properly.

Acknowledgments The work presented here is based on the principal authors' masters study (2005-2007) at Quaid-i-Azam University. We acknowledge subsequent suggestions from Dr. Nadeem Ahmed for this study. The Directorate General of Petroleum Concessions is acknowledged for the release of seismic and well data used.

Open Access This article is distributed under the terms of the Creative Commons Attribution Noncommercial License which permits any noncommercial use, distribution, and reproduction in any medium, provided the original author(s) and source are credited.

\section{References}

Ahmed N, Fink P, Sturrock S, Mahmood T, Ibrahim M (2004) Sequence stratigraphy as predictive tool in Lower Goru Fairway, Lower and Middle Indus Platform, Pakistan. PAPG, ATC

Bachrach R, Beller M, Liu Ching C, Shelander D, Dutta N (2004) Combining rock physics analysis, full waveform prestack inversion and high-resolution seismic interpretation to map lithology units in deep water: a Gulf of Mexico case study. The Leading Edge, pp 378-383

Banks BP, Warburton J (1986) Passive-roof, duplex geometry in the frontal structures of the Kirthar and Suleiman belts, Pakistan. J Struct Geol 8:229-237

Castagna PJ, Batzle LM, Eastwood LR (1985) Relationships between compressional-wave and shear-wave velocities in clastic silicate rocks. Geophysics 50(4):571-581

Gardner GHF, Gardner LW, Gregory AR (1974) Formation velocity and density-the diagnostic basics for stratigraphic traps. Geophysics 39:770-780

Gommesen L, Hansen PH, Pedersen MJ, Marsden G, Schiott RC (2004) Rock physics templates and seismic modeling of chalk reservoirs in the South Arne Field of the Danish North Sea. In: EAGE 66th conference and exhibition, Paris

Kadri IB (1995) Petroleum geology of Pakistan. Graphic Publishers, Karachi, Pakistan, pp 93-108

Kazmi AH, Jan MQ (1997) Geology and tectonics of Pakistan. Graphic Publishers, Karachi, Pakistan

Michalchuk RB (2006) Synthetic seismograms and physical properties generated from sediments in Maxwell Bay, Antarctica-a study of climate history. Middlebury, Vermont

Ravenne Ch (2002) Stratigraphy and oil: a review. Part 1: exploration and seismic stratigraphy: observation and description. Oil and Gas Science and Technology, Rev. Editions Technip, IFP, 57(3)211-250

Royle A, Bezdan S (2001) Shear-wave velocity estimation techniques: a comparison: CSEG convention, Geo-X Systems Ltd, 1

Shah SMI (1977) Stratigraphy of Pakistan. Geol Surv Pakistan, Quetta, Pakistan, vol 12, pp 43-51

Vail PR, Mitchum RM, Thompson S (1977) Seismic stratigraphy and global changes of sea level. Part 3: relative changes of sea level from coastal onlap, applications to hydrocarbon exploration. AAPG Memoir

Zaigham NA, Mallick KA (2000) Prospect of hydrocarbon associated with fossil-rift structures of the southern Indus basin, Pakistan. Am Assoc Pet Geol Bull 84(11):1833-1848 